\title{
LOS PRINCIPALES FACTORES DEL SISTEMA DE FUENTES
}

Rodolfo Delgado Gamboa
Doctorando en Derecho, Universidad Externado de Colombia; Especialista en Derecho de Familia, Universidad Autónoma de Bucaramanga, (Col); Abogado, Universidad Santo Tomás, Bucaramanga (Col). Docente Universidad Santo Tomás, Bucaramanga (Col).

E-mail: rodolfodelgadog@gmail.com

Wilson Yesid Suárez Manrique

Maestría en Hermeneutica Jurídica (C), Universidad Industrial de Santander (Col); Especialista en Derecho Procesal C), Universidad Santo Tomás, Bucaramanga (Col); Abogado, Universidad Santo Tomás, Bucaramanga (Col); Docente, Universidad Santo Tomás, Bucaramanga.

E-mail: wilsonyesidsuarez@gmail.com

\section{Resumen}

El presente escrito muestra un bosquejo de los principales elementos y procesos que se deben tener en cuenta para abordar el estudio del complejo sistema de fuentes que ostenta el ordenamiento jurídico Colombiano. Pretende, en consecuencia, desde el estudio del sistema jurídico particular, complementado con un diálogo subrepticio de concepciones teóricas de grado de abstracción mayor, mostrar que la clásica representación del sistema de fuentes desde el punto de vista netamente piramidal no ostenta la capacidad para explicar a fondo la complejidad del modelo de fuentes existente a nivel local. Por lo cual, para acercarse al estudio de tal modelo se hace imperioso agrupar diversos elementos y procedimientos, que en la mayoría de los casos han sido,en el asunto referido, pasados en silencio o se han visto de manera sectorizada por los teóricos del derecho.

\section{Palabras clave}

Fuentes, categorías deónticas, jerarquía, especialidad, autoridad, autonomía, marcos y complejidad.

\begin{abstract}
This paper shows an outline of the main elements and processes that must be taken into account for the study of complex system of sources that holds the Colombian legal system. Designed, therefore, from the study of particular legal system, complete with a surreptitious dialogue theoretical concepts more abstract level, show that the classical representation of the source system from the point of view pyramid clearly does not hold the ability to explain background model complexity of existing local sources. Therefore, to approach the study of this model becomes imperative to bring together various elements and procedures, which in most cases have been, in the case referred to, passed in silence or have been sectioned so by law theorists .
\end{abstract}

\section{Key Words}

Sources, deontic categories, hierarchy, specialization, authority, autonomy, frames and complexity 

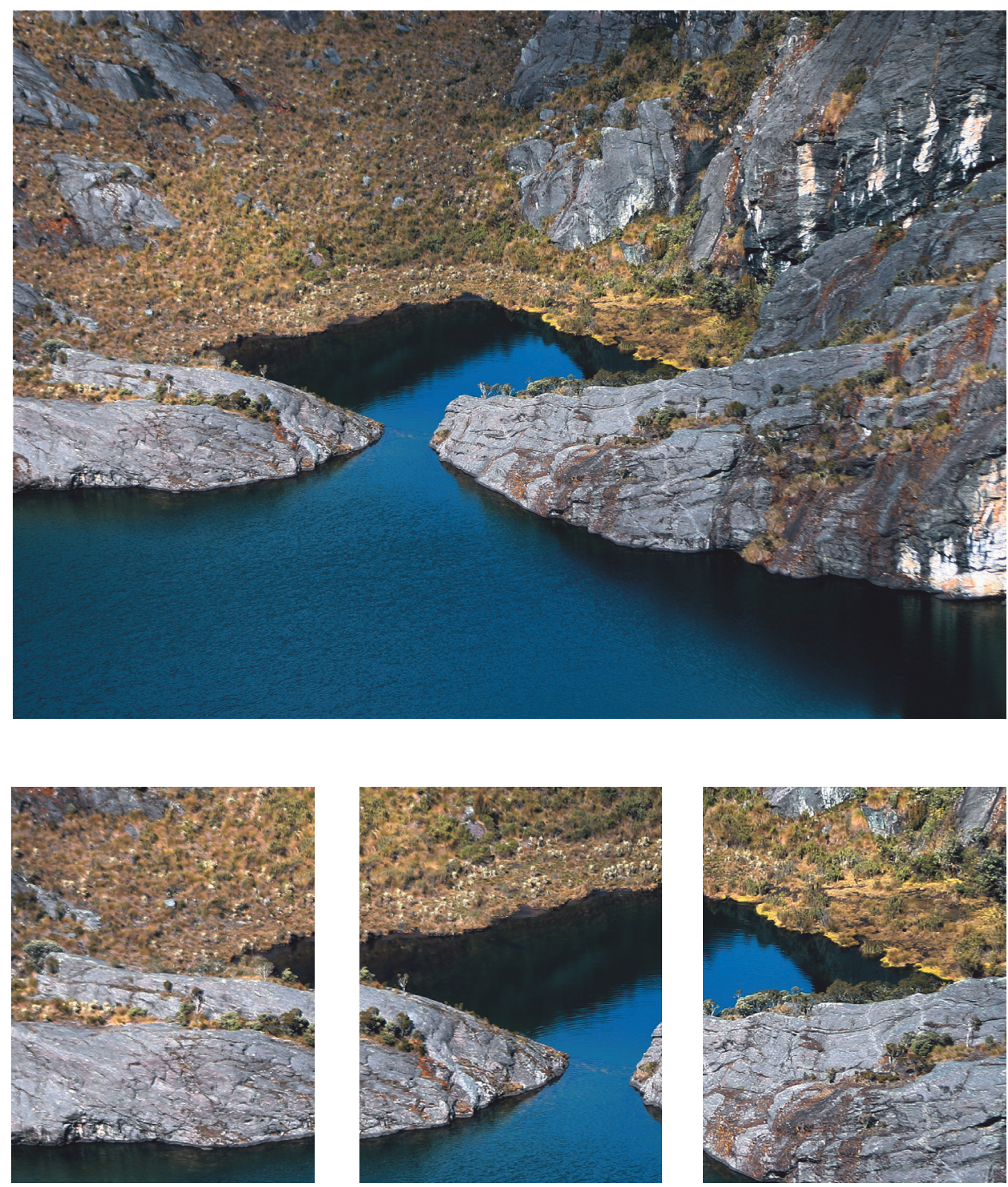

EI ojo de la laguna "La Pintada" 


\section{LOS PRINCIPALES FACTORES DEL SISTEMA DE FUENTES*}

Rodolfo Delgado Gamboa; Wilson Yesid Suárez Manrique

\section{Introducción}

El estudio de las fuentes del derecho es de los temas más relevantes en la teoría jurídica. Pese a que ha sido enmarcado en la metodología, implica concepciones acerca de la ontología y la axiología del derecho. La mayoría de los problemas acerca de las concepciones del derecho, su relación con la moral, la eficacia o la validez, pueden solventarse desde la óptica del sistema de fuentes. Las fuentes, en últimas, ostentan la capacidad de delimitar la concepción del derecho y los elementos que gravitan en torno a ésta. Se ha tratado de decir que la concepción del derecho presupone la concepción de fuentes, pero no parece nada despreciable pensar que, tal vez, sea la concepción de fuentes la que presuponga la del derecho. De hecho, así puede identificarse la clásica concepción del positivismo voluntarista.

A pesar de ser tan trascendente, la concepción del sistema de fuentes ostenta un relativo desprecio de las investigaciones jurídicas, tanto a nivel general como a nivel local. No quiere significarse con la anterior afirmación que tal temática no se haya trabajado dentro de la teoría jurídica general, sino más bien, que se ha visto, en la mayoría de los casos, como dependiente de una concepción de derecho, residual a él, o como un elemento para fundamentarlo. A nivel local ${ }^{1}$, el tema delsistema de fuentesha sido poco estudiado, debido, principalmente, a dos razones. La primera: lo embrionario del desarrollo de la teoría jurídica local. La segunda:

El presente texto es producto de la construcción del marco teórico de la Línea de Investigación Neoconstitucionalismo y Convivencia Pacífica del Grupo Neoconstitucionalismo y Derecho. Facultad de Derecho. Universidad Santo Tomás - Seccional Bucaramanga, en el se reflexiona sobre los factores del Sistema de Fuentes.

1 Referente al sistema jurídico Colombiano. 
por concepciones de derecho relativas a la eficacia interna ${ }^{2}$, se le ha dado de manera inducida a los altos órganos judiciales, especialmente, a la Corte Constitucional, la posición de ser la última palabra y el criterio de validez supremo, en tal temática. Así pues, se ha impuesto un criterio de autoridad sobre la materia, lo cual, en vez de aclarar ha ayudado a oscurecerla y deformarla.

No es fácil establecer en el ordenamiento jurídico colombiano cuáles son las fuentes del derecho, o qué formulaciones jurídicas pueden considerarse como derecho. Prima facie, podría decirse que existe un nivel de complejidad ${ }^{3}$ alto. Hay problemas en el mismo nivel de jerarquía y en los centros de producción, en los campos de regulación horizontal y vertical, y en las formas de solucionar los mismos problemas de fuentes. Ello se debe principalmente a lo pluriforme, complejo y relacional de las fuentes establecidas. A pesar de ello, los problemas de las fuentes se agravan por las facultades que la Corte Constitucional se ha abrogado (Especialmente, lo que respecta a la obligatoriedad del precedente, en lo relativo a expandir los contenidos de los derechos fundamentales, la creación de derechos fundamentales por vía de bloque de constitucionalidad o por interpretación sistemática de la Constitución, el establecimiento de relaciones y precedencia de las fuentes del derecho).

Los criterios de racionalidad para la toma de decisiones jurídicas se encuentran afectados. No puede ser un criterio de racionalidad circunstancias a vivas luces que exigen hiperracionalismo ${ }^{4}$, que no son demostrables y que presuponen cognitivismos metafísicos. De esa forma, difícilmente pueden establecerse los parámetros que deben seguir las Cortes, los juristas y los ciudadanos. Los sujetos a los cuales se dirige el derecho, deben fácilmente poder reconocerlo, de no ser así no podrían actuar de conformidad con él. Ya desde otrora, se consideraba como necesaria la promulgación de la ley a efectos de que pudiera ser obligatoria:

"para que la ley tenga el poder de obligar, cual compete a su naturaleza, es necesario que sea aplicada a los hombres que han de ser regulados conforme a ella. Esta aplicación se lleva a cabo al poner la ley en conocimiento de sus destinatarios mediante la promulgación. Luego la promulgación es necesaria para que la ley tenga fuerza de tal."

La importancia de las líneas transcritas refiere a que el derecho ostenta como requisito de implicación intensiva el conocimiento de las personas a las cuales se dirige, de no ser así no se podría reprochar su desobediencia. No puede pensarse que con la concepción actual de fuentes pueda una persona medianamente racional

2 Según Bierling: «Derecho en sentido jurídico es, en general, aquello que las personas que conviven en alguna comunidad reconocen recíprocamente como norma y regla de esta convivencia.» ALEXY, Robert. El concepto y la validez del derecho. Barcelona: Gedisa. 2004.

3 Cfr. BOBBIO, Norberto. Teoría General del Derecho. Bogotá: Editorial Temis. 2.002.

4 Cfr. BERNAL, Carlos. El Neoconstitucionalismo y la normatividad en el derecho. Bogotá: Universidad Externado de Colombia. 2007.

5 Tomas de Aquino. SummaTeologiae, primera sección de la segunda parte, Cuestión 90Artículo 4. 
conocer el derecho, saber bajo qué parámetros debe basar su conducta. Es inexigible con medianos trazos a una persona que se comporte de tal o cual manera cuando no se puede establecer por esta cuales son los mandatos, prohibiciones o permisiones que se le imputan ${ }^{6}$. Se requieren unos mínimos referentes para la toma de decisiones racionales.

Se cree que la forma más racional de solventar el problema de fuentes es entender, especialmente en un estadio constitucional democrático, a la ley como el principal elemento de racionalidad para la toma de decisiones. Además de ser producto de un consenso ayuda a reforzar el papel de integración del derecho. Que sea un adecuado criterio racional no significa que sea el único o el de más validez, sino el primero para revisar; sería algo así como decir que: el que cuestione la ley ostenta la carga de la prueba de fundamentar su cuestionamiento. Empero, para sostener ello, hay que aclarar muchas cosas primero.

Para sustentar lo anterior, el escrito se divide en tres secciones ${ }^{7}$. En la primera, se muestran ciertas características que bosquejan los principales elementos de las teorías generales de las fuentes del derecho. En la segunda, se trata de describir los elementos principales del sistema de fuentes existente en el ordenamiento jurídico interno. Por último, amanera de conclusión, se establecen los elementos más importantes que se obtiene como producto de la síntesis de las dos secciones anteriores.

\section{Primera Sección}

\section{Principios y normas}

En los ordenamientos jurídicos modernos pueden rastrearse básicamente dos especies de reglas: las normas y los principios ${ }^{8}$. Las normas son mandados deónticos, es decir, mandan prohíben o permiten. El carácter de las normas o se cumple o no

6 Por ejemplo: las concepciones acerca de figuras como los valores, principios, derechos innominados, interpretaciones sistemáticas, bloque de constitucionalidad, relaciones entre la Constitución y la ley respecto de la jerarquía y exclusiones, no son cognoscibles por todos los ciudadanos, luego no parecen ser el mejor mecanismo de racionalidad para la toma de decisiones. Empero, tales concepciones parecen haber servido a los jueces y a ciertos juristas para resolver determinados asuntos. Luego, podría pensarse que el discurso de los altos tribunales ostenta diferentes destinatarios. Ello parecería ser la solución más cómoda. Pero acarrea el problema de que los ciudadanos van a tener como criterios ciertos trazos y los jueces los van a medir con otros. Se considera esto inaceptable.

7 Cuenta con componentes empíricos delimitados y normativos, aunque a veces se entremezclen tanto que se confundan.

8 Cfr. ALEXY, Robert, Teoría de los derechos fundamentales, Madrid: Centro de Estudios Políticos y Constitucionales, Impreso en Solana e hijos, A.G., S.A., 2002. BERNAL, Carlos. El Neoconstitucionalismo y la normatividad en el derecho. Bogotá: Universidad Externado de Colombia. El Neoconstitucionalismo a Debate. Bogotá: Universidad Externado. 2007 
se cumple. Tales normas suelen aplicarse mediante la subsunción, o, lo que es lo mismo, el conocido silogismo de la forma AAA. Los principios son mandatos de optimización que ordenan que algo sea realizado en la mayor medida posible, dentro de las posibilidades fácticas y jurídicas ${ }^{9}$, prima facie, no tiene el mismo carácter de las normas. Lo que mandan los principios puede cumplirse en diversos grados; es decir, no puede predicarse que tales se cumplen o no se cumplen. Tales principios suelen aplicarse mediante la ponderación.

No obstante lo anterior, en donde se ha establecido una diferencia de la aplicación de las normas y principios, entre la subsunción y la ponderación, se hace necesario efectuar una precisión. Se cree conveniente precisar que la ponderación en sí no es un mecanismo de aplicación al caso concreto, sino que es un mecanismo para crear una norma particular de precedencia. Pues, luego que se establece la norma particular de precedencia se efectúa una subsunción mediante la cual se resuelve el caso concreto. La ponderación es un elemento para fijar una norma jurídica universal: la premisa mayor; mediante la cual se resuelve el caso. La aplicación de la norma creada se efectúa mediante la subsunción. Así, pues, en últimas, normas y principios se aplican mediante la ponderación.

\subsection{Justificación Interna y Justificación Externa}

Generalmente se distingue entre justificación interna y justificación externa, según se trate de justificar el paso de las premisas a la conclusión o de justificar las premisas mismas.

\section{Justificación Interna}

La forma más simple de la justificación interna está representada por la aplicación silogística. Para el caso de la lógica de predicados, se ostenta la siguiente estructura:

1) $(x)(H x \rightarrow O C x)$

2) $\mathrm{Ha}$

3) $\mathrm{OCa}$

En la anterior representación $x$ significa una variable individual, $H$ un supuesto de hecho determinado, $C$ una consecuencia jurídica determinada, y $a$ una constante de individuo. De manera simplista se dice que el enunciado representado en 1) significa una norma de carácter general que es aplicable a todos los sujetos representados por $x$. El enunciado 2) es una descripción fáctica según la cual el sujeto $a$ ha ejecutado la

9 Cfr. ALEXY, Robert, El Concepto y la Validez del Derecho, Barcelona: Gedisa, 2004. ALEXY, Robert, Teoría de los derechos fundamentales, Madrid: Centro de Estudios Políticos y Constitucionales, Impreso en Solana e hijos, A.G., S.A., 2002. ALEXY, Robert, Teoría del Discurso y los Derechos Humanos, Bogotá: Universidad Externado de Colombia. 2004. 
acción descrita por $H$. El enunciado 3) significa la decisión o la consecuencia jurídica que se produce respecto de $a$ por haber cumplido el supuesto fáctico 2). En otras palabras: 1) Es la premisa mayor, 2) la premisa menor, y 3) la conclusión. Así pues, véase el siguiente ejemplo:

1. Los jueces están sometidos al imperio de la ley

2. José es juez

3. José está sometido al imperio de la ley

"Las reglas de justificación interna están sujetas al requisito de que toda decisión jurídica se debe deducir lógicamente de una norma universal."10. Tal afirmación de apología a la deducción jurídica, se basa en el requisito de justicia formal en que se apoya el principio de universalidad.

La justificación interna garantiza cierto grado de racionalidad en la toma de decisiones jurídicas. Una decisión judicial, bajo esta óptica, es racional si se basa en premisas adecuadas, jurídica y factualmente, si se deduce lógicamente de ellas. No obstante, se hace necesario complementar tal racionalidad con la racionalidad de las premisas. Pues, que la decisión judicial pueda sustraerse de manera adecuada de las premisas, no implica que las premisas estén justificadas.

\section{Justificación externa}

La justificación externa refiere a la justificación de las premisas de la justificación interna. Acá no se trata de justificar como correcto el paso de las premisas a la conclusión, sino de justificar las premisas en las cuales se basó la conclusión. Es decir, en los ejemplos signados se referiría a la justificación de $(x)(H x \rightarrow O C x)$ y $H a$ ("Los jueces están sometidos al imperio de la ley" y "José es juez").

Como fácilmente se ve la justificación de las dos premisas es de naturaleza diferente, la primera refiere a una regla jurídica válida y la segunda refiere a la justificación de una circunstancia factual. La primera es de derecho y la segunda de hecho. Por el tema planteado, se dejará de lado la justificación factual y se centra la atención en la justificación de la regla jurídica.

La justificación externa de la premisa jurídica tiene por finalidad mostrar que existe una regla jurídicamente válida que regula el caso. Consiste en justificar racionalmente el criterio de racionalidad de la justificación interna. La forma de justificar tal cosa se hace mediante la demostración de los criterios de validez de la premisa mayor. Se ha de demostrar que la premisa mayor en la toma de la decisión judicial corresponde a una norma válida dentro del ordenamiento jurídico.

Un gran número de problemas judiciales, de los litigios que llevan a posiciones

10 FETERIS, Eveline, Fundamentos de la argumentación Jurídica: revisión de las teorías, Bogotá: Universidad Externado de Colombia, 2007. p, 167. 
extremas y contradictorias a las partes, no se dan tanto en el hecho de que existan problemas en la justificación interna de las decisiones judiciales, sino, más bien, se debe a problemas de las premisas jurídicas utilizadas. Las partes y el juez pueden utilizar diferentes premisas jurídicas para regular un caso. Puede decirse que "los problemas principales de la justificación legal están ligados a la justificación externa""1. El problema de la justificación interna es trivial ${ }^{12}$. "El problema central de la interpretación jurídica es la elección de la premisas y su contenido"13. Lo cual, remite a problemas de fuentes del derecho. Pues, de acuerdo a las fuentes que se utilicen las premisas serían diferentes y se justificarían de modo distinto.

\subsection{Concepciones primarias de las fuentes}

Las clásicas concepciones de derecho natural y positivo, en la antigüedad ostentaban fuentes bien marcadas. Al siglo $\mathrm{V}$ a.C. puede rastrearse las tres concepciones clásicas del iusnaturalismo ${ }^{14}$, las cuales soportan el origen remoto de las fuentes del derecho. La primera, es la línea voluntarista, según la cual,

"la ley es justa, absolutamente valida, superior a las leyes positivas humanas porque está dictada por una voluntad superior a la humana, como en el caso de las divinas leyes no escritas de la Antígona de Sófocles, y que podemos denominar iusnaturalismo voluntarístico" $"$.

La segunda, es la línea naturalista, según la cual, la ley natural es superior porque proviene directamente de la naturaleza, su fuente ya no es la voluntad de una entidad superior, sino la mima naturaleza, es una especie de instinto. La tercera, es la línea racionalista, según la cual el derecho proviene de la recta razón, su fuente no es ni la voluntad ni la propia naturaleza ${ }^{16},{ }^{17}$.

Por su parte, las doctrinas positivistas desde la antigüedad ostentaron el acento

11 Según Aarnio "los problemas principales de la justificación legal están ligados a la justificación externa". AARNIO, Aulis, Lo racional como razonable. Un tratado sobre la justificación jurídica. Trad. de Ernesto Garzón Valdés. Madrid: Centro de Estudios Constitucionales, 1991, p, 120.

12 Ibíd.

13 FETERIS, Eveline, Fundamentos de la argumentación Jurídica: revisión de las teorías, Bogotá: Universidad Externado de Colombia, 2007. p, 194.

14 FASSÓ, Guido. Historia de la Filosofía del Derecho. Madrid: Ediciones Pirámide, S.A. 1996, p, 35 .

15 Ibídem.

16 Guillermo de Auxerre distingue tres clases de derecho natural: universalissimun, universalius, y especiale. El primero es el que está por encima de todas las cosas. El segundo, es el que dice la naturaleza. El tercero es que dicta la razón. FASSÓ, Guido. Historia de la Filosofía del Derecho. Madrid: Ediciones Pirámide, S.A. 1996, p, 210.

17 Se aclara que, por ejemplo, en al doctrinas panteísticas, Dios, naturaleza y razón, son una misma entidad, por cuanto el iusnaturalismo se vuelve uno solo. 
en el voluntarismo. Es derecho lo dictado por la voluntad del Estado ${ }^{18}$. Quizás el antecedente más próximo de tal concepción sea Marsilio de Padua. Se dice que en sus concepciones se está

"ante la primera formulación precisa de la doctrina que se llamará positivismo jurídico, es decir, la reducción del derecho al mandato coactivo del Estado. ${ }^{19}$ "

Por parte del iusnaturalismo la línea que más ha avanzado es la racionalista. La cual, permitió desligar al derecho de la religión, de la voluntad y de la historia. Sus implicaciones llegaron hasta los lugares más específicos de los cantones del derecho. Como ésta es la línea del iusnaturalismo que más ha avanzado, fácilmente, podría pensarse que respecto del positivismo existe una contraposición, desde otrora, entre voluntarismo y racionalismo.

\subsection{El carácter de las fuentes}

Las fuentes del derecho se pueden clasificar desde el punto de vista del carácter para su utilización ${ }^{20}$. Según exista la necesidad, posibilidad, imposibilidad o normación para su utilización. Así pues, podría establecerse una clasificación de cuatro carriles: fuentes que deben, pueden, no deben o deberían utilizarse.

En los sistemas jurídicos continentales, de forma general, la legislación positiva es una fuente que debe utilizarse. Al igual, que en los sistemas del common-law los precedentes judiciales constituyen una fuente jurídica. Esta clase de fuentes "que son formalmente obligatorias, constituyen fuentes que debe utilizarse" ${ }^{21}$. Son fuentes respecto de las cuales puede decirse que son necesarias.

En cambio, en ocasiones se utilizan fuentes jurídicas que pese a que no son obligatorias ayudan a fundamentar la elección. Estas fuentes ayudan a que la justificación sea más fuerte no obstante son parasitarias de una fuente obligatoria. Por ejemplo, de forma general, la utilización de la jurisprudencia en los sistemas continentales, donde se caracteriza la ley como fuente obligatoria, constituye una fuente que puede utilizarse para fundamentar la elección. Tales fuentes no son necesarias sino posibles.

En ocasiones, determinados actos o hechos no constituyen fuentes jurídicas, pues su utilización ha sido prohibida de forma directa o indirecta. Cuando se dice, por ejemplo, que la costumbre contra ley no es fuente de derecho, se prohibe de manera

18 Cfr. BOBBIO, Norberto. El problema del positivismo jurídico. Santa Fe de Bogotá: Editorial Temis. 1997.

19 FASSÓ, Guido. Historia de la Filosofía del Derecho. Madrid: Ediciones Pirámide, S.A. 1996, p, 212.

20 Según Peczenic, existen "fuentes que se deben utilizar, fuentes que se deberían utilizar y fuentes que se pueden utilizar”. FETERIS, Eveline, Fundamentos de la argumentación Jurídica: revisión de las teorías, Bogotá: Universidad Externado de Colombia, 2007. p, 224.

21 Ibídem. 
directa dicha fuente. Cuando se dice que tal o cuales cosas son fuentes y que otras no son fuentes directas, se prohíbe indirectamente la utilización de determinadas fuentes como fuentes directas. En estos dos casos se está ante fuentes imposibles.

Además, existen otras fuentes que poco tienden a utilizarse y a tener fuerza vinculante, empero prestan gran ayuda en la labor jurídica, estas son las fuentes que deberían utilizarse. Por ejemplo, la doctrina en los sistemas jurídicos continentales es una fuente que debería utilizarse, no obstante, no es fuente obligatoria y además se encuentra subordinada a las demás fuentes que deben utilizarse y a las fuentes que pueden utilizarse. La calificación de los teóricos del derecho da argumentos de autoridad para ser considerados como una fuente ideal del derecho. La mayoría de los avances en el derecho positivo está ligada a los criterios de racionalidad dados por los dogmáticos.

La clasificación planteada es una herramienta importante para tratar de bosquejar la solución a algunos de los problemas de las fuentes del derecho, empero presenta unos inconvenientes que hay que advertir. En ocasiones no es fácil determinar ante qué clase de fuente se está. Las diferentes fuentes pueden tener límites vagos y la capacidad de transformarse o ser transformadas. Pues, en ocasiones no es fácil determinar si se está ante una fuente necesaria o posible, o algunas regulaciones que eran permitidas se transformaron en necesarias o imposibles, o se ha hecho pasar ideales por necesarias o imposibles.

\subsection{La norma fundante}

El problema de las fuentes, su necesidad, posibilidad, imposibilidad, o idealidad, se subsume en últimas en el problema de la validez del derecho. La determinación de validez que se plantea, en principio, deja de lado los elementos de eficacia y corrección material $^{22}$. Para determinar si una norma jurídica es una norma valida, se ha dicho, de forma general, que se han de revisar cuestiones formales y materiales. Las formales aluden a que haya sido dictada por el órgano competente mediante el procedimiento establecido. Las materiales aluden a que no se infrinja una norma de orden superior. Empero, estas concepciones presuponen por sí mismas el concepto de validez. Para calificar a una autoridad como competente - o para referir un procedimiento previo o normas de carácter superior- se debe preestablecer el concepto da tal adjetivo. Lo cual, para resumir las cosas, conllevaría un regreso al infinito.

Para saltar el regreso al infinito y establecer el fundamento de validez de las normas jurídicas por fuera de ellas mismas, se hace necesario acudir a la concepción de "normas fundantes". Tales normas pueden ser de tres clases: analíticas, normativas y empíricas. No obstante, acá se efectúa especial énfasis en la norma fundamental

22 ALEXY, Robert. El concepto y la validez del derecho. Barcelona: Gedisa. 2004. VIGO, Rodolfo Luis, El Iusnaturalismo actual. México: Fontamara. 2003. p, 93. 
analítica, y, de manera simplista se dirá que la principal diferenciación con la empírica, es que ésta es "cuestión de hecho".

La norma fundante analítica se fundamenta, principalmente, en la respuesta al siguiente cuestionamiento ${ }^{23}$ ¿Por qué vale una norma?" 24 Bajo esta óptica, que "una norma valga significa que obliga" 25 . Luego, saber por qué una norma obliga no puede ser explicado "mediante la verificación de un hecho empírico, de que algo sea no puede seguirse que algo deba ser, así como, que algo sea debido, no puede seguirse, que algo sea." ${ }^{26} \mathrm{Al}$ no encontrar el fundamento de la validez del ordenamiento jurídico en la observación o en un hecho, se afirma que "el fundamento de la validez de una norma sólo puede encontrarse en la validez de otra norma" ${ }^{27}$. Se establece la necesidad de una norma que fundamente la validez de las demás normas del sistema jurídico.

Una norma fundante es una norma que fundamenta la validez de las demás normas del ordenamiento jurídico fuera de ella misma. Si alguien quiere decir que una Constitución vale jurídicamente o que es obligatorio comportase de conformidad con la Constitución se debe presuponer la existencia de una norma fundamental que diga que es jurídicamente válido comportase según los mandatos de la Constitución. Es decir, una norma que avala la validez de las disposiciones del texto constitucional. De esta norma fundante resulta especialmente importante lo que concierne a sus funciones y clases ${ }^{28}$.

La norma fundamental tiene tres tareas principales: producir el cambio de categoría, el establecimiento de los criterios para la determinación del derecho, y la unidad al sistema jurídico. Produce el cambio de categoría porque ella determina el cambio del ser al deber ser, el cambio de lo fáctico a lo jurídico. Establece criterios para la determinación del derecho por cuanto determina qué acciones o hechos pueden

23 El cuestionamiento es relativo a la presuposición del derecho como un orden normativo.

24 KELSEN, Hans, Teoría Pura del Derecho, México: Editorial Porrúa, 2000, p, 201.

25 Ibídem

26 Ibídem.

27 Ibídem.

28 Se pasa por alto el tema de la naturaleza de la norma fundante, pues, tales concepciones pese a que son importantes no guardan del todo relación con el objeto del escrito. Las características de la naturaleza de la norma fundante son las siguientes: es un presupuesto necesario, es un presupuesto posible, es una norma pensada, y no admite fundamentación. Es un presupuesto necesario porque no de otra forma puede explicarse el concepto de validez dentro de las concepciones positivistas. Es presupuesto posible por cuanto si se estudia desde las concepciones del realismo jurídico o del iusnaturalismo no se haría necesaria la configuración de una norma fundante. Es una norma pensada por cuanto no es establecida como el fruto de un querer o como el producto de la voluntad de un ente, sino que más bien es un producto del pensamiento. La norma fundante no tiene fundamentación por cuanto ella es el fundamento último de todo el ordenamiento jurídico, es la norma superior, la cual no se encuentra fundamentada en ninguna otra norma. 
verse como creadores de derecho ${ }^{29}$. Dota al sistema jurídico de unidad por cuanto todas las normas de un sistema jurídico han de poder deducirse de una misma norma fundante; todas aquellas normas que se deriven de la norma fundante constituyen una unidad, un sistema jurídico, "un sistema de normas, un orden normativo ${ }^{30 "}$.

Esta norma fundante constituye el presupuesto lógico trascendental de la validez del sistema jurídico, este fundamento común de validez para los sistemas jurídicos puede ser de dos tipos diferentes: un tipo estático y un tipo dinámico. Las normas fundantes del tipo estático "valen por su contenido", "pues el contenido de las normas puede ser subsumido como de lo particular a lo general" 31 . Las normas fundantes de tipo estático prestan el fundamento de la validez, en el contenido de las normas que conforman el ordenamiento. Es decir, que una norma no vale solamente porque sea emitida por determinado órgano mediante cierto procedimiento, según lo dispone la norma fundante, sino que además, se requiere que el contenido de las normas derivadas esté de acuerdo con el contenido de la normas de normas, es decir, que el contenido de las normas pueda inferirse del contenido de la norma fundante. Por tanto, y al poseer esta calaña de normas un núcleo de contenido que se sitúan en el núcleo de contenido de la norma última, hace que el sistema sea de tipo estático. Pues, la validez de las normas derivadas estará condicionada a que su contenido se pueda deducir del contenido de la norma fundante.

En contrapartida, existen normas que prestan el fundamento de validez al sistema jurídico con "un principio dinámico"32. Pues en esta clase de normas, ya no se tiene en cuenta el contenido. Al no tenerse en cuenta el contenido, puede notarse que éste puede ser cualquiera, y al ser cualquiera es dinámico. Este tipo de normas simplemente efectúan "el facultamiento a una entidad normadora" 33 . Es decir, que dan la potestad para dictar las normas, por ello en tal sistema serán válidas las normas dictadas de conformidad con la norma fundante, con la potestad por ella concedida.

"Es la instauración del hecho fundante de la producción del derecho, es una Constitución lógico-jurídica para diferenciarla de la Constitución jurídicopositiva" 34 .

Con base en lo expuesto, se afirma que podría existir ordenamientos jurídicos que respondan al principio dinámico, "de ahí que cualquier contenido que sea, puede ser derecho" 35 , y otros que acentúen el principio estático, al existir materias que deban deducir su contenido de la norma fundante o respetar ciertas restricciones dadas por

29 Cfr. ALEXY, Robert. El concepto y la validez del derecho. Barcelona: Gedisa. 2004. VIGO, Rodolfo Luis, El Iusnaturalismo actual. México: Fontamara. 2003. p, 106.

30 KELSEN, Hans, Teoría Pura del Derecho, México: Editorial Porrúa, 2000, p, 202.

31 Ibíd. p, 203.

32 Ibíd. p, 204.

33 Ibíd. p, 204.

34 Ibíd. p, 206.

35 Ibíd. p, 205. 
ésta. En el primer caso, el legislador puede emitir cualquier derecho, en el segundo, el contenido de las disposiciones legislativas es restringido por el respeto a ciertos alcances de las normas de superior jerarquía.

En los ordenamientos jurídicos complejos puede verse una interrelación de las dos clases de principios. Existen campos o márgenes de discrecionalidad legislativa y existen campos restringidos para el legislador. Es decir, algunos ámbitos del ordenamiento jurídico parecerían regularse con autonomía, por la acentuación del tipo dinámico, y en otros parece existir dependencia de tipo estática. Ello parece suceder por el hecho que existen, con cierto carácter, campos regulados y campos no regulados por la Constitución, por la forma de tratar la fuente o las fuentes del derecho.

\subsection{Centros de producción, contenidos y solución de aporías en las fuentes}

El tema de las fuentes puede revisarse desde el punto de vista del sujeto que las emita -en sentido genérico, puede ser tomado como centros de producción- y del contenido de éstas. Si la fuente fuera una sola, difícilmente existirán conflictos. La forma de determinar el derecho válido sería la procedencia del derecho. No obstante, puede darse el caso que una misma fuente autorizada para ello emita derecho contradictorio, en tal caso se estaría ante un problema de contradicción o de incoherencia de la entidad encargada de emitir derecho ${ }^{36}$. Ese problema se da cuando por ejemplo para una misma ocasión se manda hacer y no hacer la misma conducta, o se permite hacer algo y a la vez se prohíbe. Es decir, el ente encargado de emitir el derecho puede ser considerado como irracional o incoherente. Tal problema puede solucionarse mediante reglas de precedencia o prevalencia tales como la temporalidad, especialidad y materia entre otros.

Si existieran varios entes o centros encargados de emitir derecho los problemas tienden a aumentar. Si dos o más entidades están facultadas para expedir derecho puede darse el caso que no se contradigan o que se contradigan. Si no se contradicen no existirá problema que solucionar. Solamente si se da el caso de que se contradigan ellas mismas, caso en el cual simplemente valdría lo relatado al final del párrafo anterior.

Pero, para solucionar contradicciones, en caso de que se contradigan, puede establecerse alguna subordinación de una entidad a otra entidad, o pueden instaurarse campos de regulación o de especialidad, o puede instituirse la decisión de un tercero. En el caso de los rangos de superioridad es que se establece que determinada autoridad inferior debe acatar los dictámenes de una entidad superior, por tanto, no puede controvertirla en ninguna de sus disposiciones. Así pues, si $a$ es superior a $b$, en caso de que $a$ regule determinada situación y $b$ la regule en un sentido diferente,

36 WRIGHT, Georg Henrik Von. Normas, verdad y lógica. Fontamara, México, 1997. p, 8. 
tendría prevalencia la decisión de $a$. En el caso de establecimiento de especialidad no se tiene en cuenta, en primera medida, la existencia de criterios de superioridad entre las entidades que emiten el derecho sino que el acento recae en que ciertas materias han de ser reguladas por determinadas entidades, por tanto, cuando existe conflicto por que determinada materia fue regulada de manera distinta por diferentes entes ha de preferirse la regulación del centro especializado en ella. Así pues, si $a$ es especialista para regular la temática $x$ y la regula en la forma $p$, ante una regulación de la fuente $b$ en la materia $x$ de la forma $r$, prevalecería la regulación de efectuada por $a$. En el tercer caso, ante regulaciones distintas, parecía cómodo acudir a un tercero que determine cuál es la regulación válida dada, cuál de las regulaciones en conflicto ha de preferirse. Esta forma de evitar el conflicto puede implicar las dos formas señaladas. ${ }^{37}$ Así pues, si $a$ regula la temática $x$ en la forma $p$, ante una regulación de la fuente $b$ en la materia $\mathrm{x}$ de la forma $r$, se tendría que acudir a $c$ para que estableciera cuál de las dos regulaciones debería prevalecer.

Lo anterior tiene la virtud de solucionar el problema de fuentes de una manera más o menos clara y precisa, empero esconde problemas más complicados. Por ejemplo, que no siempre existen criterios de subordinación o de especialidad, o que esos criterios no son claros, o que ninguna entidad es superior, o que no existe el tercero encargado de determinar la prelación, o que no puede establecerse de manera clara si existen determinados mandatos ni el alcance de éstos.

No existe criterio de subordinación cuando la fuente del derecho prima facie tiene la misma jerarquía. Tal es el caso, por ejemplo, del evento en que la Constitución, con dos artículos de igual jerarquía, regule dos asuntos de diferente manera. El determinar cuál de las dos regulaciones es la regulación válida implica juicios diferentes al de la superioridad jerárquica. No es viable aplicar el criterio de especialidad cuando o ninguna de las dos fuentes lo posee o se está en un campo en el cual no es claro cuál de las dos fuentes lo posee. Si la fuente $a$ es especialista en $x$ y $b$ es especialista en $y$ y se está en un campo $z$ ninguna de las dos fuentes sería especialista, o si se está en un campo que no pueda fácilmente delimitarse como $x$ o como $y$ no podría establecerse por tal criterio cuál es la fuente válida. No es viable aplicar el criterio de la determinación de un tercero decisor cuando tal no se ha establecido, cuando existe un conflicto entre dos fuentes y no se ha establecido quien deba dirimirlo. Si a dispone $\mathrm{x}$ y b y y no existe $c$ que diga cuál es la regulación válida o $c$ no tiene competencia para ello. No obstante, en la mayoría de los casos suele ser este procedimiento, el de encargar a un tercero -Corte Constitucional- uno de los principales comodines, usados adrede o de manera inducida, para la solución de los problemas de fuentes.

37 Esto explicaría de cierta forma las funciones de las Cortes Constitucionales. 


\subsection{Familias jurídicas}

El concepto de familias jurídicas es útil para mostrar los rasgos principales de la relación entre la jurisprudencia, la ley y la constitución. El concepto de familias jurídicas se cimienta en los elementos de continuidad que pueden presentar determinados ordenamientos jurídicos. Trata de reducir y agrupar los ordenamientos existentes en categorías más abstractas que puedan englobar un número plural de ellos. Así pues, Esmein, al tomar como criterios clasificatorios las fuentes del derecho y su estructura general, dividió los derechos existentes en las familias jurídicas: romana, germana, anglosajona, eslava e islámica. René David, al tomar como criterios de clasificación la técnica jurídica y los principios filosóficos, dividió las familias jurídicas en: romano-germánico, de common-law, socialistas, y filosóficos y religiosas. De forma más sofisticada y completa, Konrad Zweigert y Hein Kotz, al tomar como criterio clasificatorio el estilo jurídico, lo cual engloba caracteres tales como "el trasfondo y desarrollo histórico, modo de pensamiento jurídico, instituciones características, fuentes e ideología", propusieron la clasificaciones de las siguientes familias jurídicas: romana, germana, nórdica, de common-law, socialista, de lejano oriente, islámica e india ${ }^{38}$.

Una de las cosas que tienen en común las anteriores clasificaciones es el hecho que existe una diferenciación entre las familias jurídicas romanas (o romano-germanas) y las anglosajonas (o de common-law). Dicha diferenciación representa rasgos comunes esenciales entre los ordenamientos que corresponden a la misma familia, y rasgos esenciales diferentes entre los ordenamientos que pertenecen a diferentes familias. Empero, se aclara, que las similitudes y diferenciaciones que existen entre los miembros de las distintas familias no corren con parejo resultado; pues, pueden existir elementos de familias distintas que se relacionan en diversas medidas.

En el origen de los dos sistemas referidos existen ciertas diferencias marcadas. El derecho romano-germano se formó con base en el antiguo derecho romano; mientras que, por su parte, el common-law se formó por la práctica de los jueces de Inglaterra ${ }^{39}$. En el primer sistema, la ley es preponderante, se han establecido diversos códigos en donde se consignan mandatos abstractos de carácter deóntico; por su parte, en el common-law, las reglas dadas por los jueces son menos abstractas que las regulaciones legales. En el sistema romano-germano las leyes sientan las bases sociales para un desarrollo en el futuro; en el common-law, lo que se quiere

38 Cfr. S ANTOS, Boaventura de Sousa. La globalización del derecho. Los nuevos caminos de la regulación y la emancipación, Bogotá: Universidad Nacional de Colombia - facultad de Derecho, Ciencias Políticas y Sociales Instituto Latinoamericano de Servicios Legales Alternativos (ILSA), 1998.

3931 "Tradicionalmente las reglas de derecho concernientes a la justicia, al procedimiento, a las probanzas y a la ejecución de las decisiones provenientes de la administración de justicia son las más relevantes para los abogados del common-law, no así las reglas relativas al fondo del derecho." 
es solucionar un conflicto en especifico, restablecer cierto orden alterado, "la paz se encuentra amenazada entonces se procura su restablecimiento", y no dar un fundamento de bases sociales o de desarrollo para el porvenir. El derecho romanogermano en principio estuvo atado al derecho civil, en cambio, el common-law estuvo más referido al derecho público. Aquel, se instauró para regular relaciones entre ciudadanos y éste para regular situaciones entre los ciudadanos y el Estado ${ }^{40}$.

De forma más específica: la jurisprudencia es fuente formal de derecho en los ordenamientos jurídicos anglosajones. Los típicos casos de estas familias son el modelo inglés y el norteamericano, en donde, respectivamente, la Cámara de los Lores del Reino Unido y la Corte Suprema Federal de Estados Unidos, juegan un papel preponderante. En estos ordenamientos la ley juega un papel residual. En cambio, la ley es fuente formal por excelencia en los ordenamientos jurídicos de corte romano-germano, como es el caso de la mayoría del derecho continental. Los típicos casos de estas familias son Francia e Italia. En donde, la ley como producto democrático juega un papel preponderante. Acá, la jurisprudencia es residual.

No obstante las diferencias iniciales, se ha dado un progresivo acercamiento entre los dos sistemas. Las diferencias entre cada una de las familias jurídicas no es como en otrora. Algunas situaciones del modelo anglosajón que eran completamente subsidiarias en el romano-germano han adquirido importancia en éste último y, a su vez, algunas situaciones del modelo romano-germano que eran completamente subsidiarias en el anglosajón, han adquirido importancia en este último. Así pues, en Francia la jurisprudencia aunque no constituye una fuente de derecho, algunos fallos de la Corte de Casación o por el Consejo de Estado Francés, en determinadas circunstancias "tienen una autoridad muy similar a la de la ley"

"en Inglaterra la leyes son también numerosas y desempeñan una función tan importante como la legislación en Francia y han dejado, con frecuencia, de ser interpretadas literal y restrictivamente." ${ }^{.2}$

Una de las formas de diferenciación entre los dos modelos es el de la obligatoriedad del precedente. Puede, prima facie establecerse tres distintos grados. Uno, en la cual, el precedente es totalmente obligatorio tanto para quien lo emitió como para los subordinados a él, es decir, el precedente tiene la misma fuerza de la ley. Otro, en el cual, el precedente es más o menos obligatorio, pero los jueces pueden apartarse de él y aducir razones. Y, el último caso, en el cual el precedente no es obligatorio. La anterior visión trifocal puede ser enriquecida con elementos adicionales como, por ejemplo, las zonas de excepción de obligatoriedad, la relación con la ley y el grado de las razones que deben aducirse, entre otros..

40 "las disputas entre particulares únicamente podrían someterse a las Cortes del sistema de derecho common-law cuando amenazara de alguna manera el interés de la corona o del reino"

41 DAVID, René, Los grandes sistemas jurídicos contemporáneos, Madrid: Aguilar, 1973. p, 25.

42 Ibíd. p, 26. 


\section{Segunda Sección}

\subsection{Modelo simple}

Comúnmente se ha establecido y entendido en nuestro país, quizás por influencias foráneas, el sistema de fuentes desde una confección piramidal, en donde se establece que la Constitución está en la cima y de ella se subordinan las demás fuentes. Así pues, se dice que las leyes se subordinan y deben estar de conformidad con la Constitución, y, a su vez, los actos administrativos deben estar de conformidad con la ley. Existen fuentes de mayor y menor jerarquía según el valor de su validez. Ilustrativamente se recurre a concepciones piramidales.

Según el artículo 4 de la Constitución, ésta es la Norma de normas. Según lo dispuesto en el artículo 241 y 237 de la Constitución Política, las leyes y ciertos decretos deben acomodarse a los postulados de la Constitución, para lo cual se ha encargado (en un sistema prima facie difuso) a ciertos cuerpos colegiales que velen por ello. De lo cual se deduce que las normas como leyes y los decretos deben acoplarse a la Constitución. A su vez, los actos administrativos deben subordinarse a las gradas normativas de validez superior. Existe un poder de las normas constitucionales que conllevan al deber de que las normas de grado inferior las respeten. Así, pues, la Constitución será productiva y las normas que a ellas se subordinan normas ejecutivas de ella. Y, a su vez, las normas que deben respecto de la Constitución son normas de poder respecto de las normas de inferior jerarquía; por lo cual, las normas ejecutivas se convierten en normas productivas respecto de las subordinadas a ellas. Las leyes ostentan poder respecto de los actos administrativos, éstos ostentan deber respecto de las leyes. Las leyes son ejecutivas respecto de la Constitución, pero productivas respecto de los actos administrativos.

Se citan tres extractos jurisprudenciales, de la sentencia C 037 de 2000, de la Corte Constitucional, que se cree, reflejan de manera muy ilustrativa la concepción del sistema de fuentes piramidal:

"El ordenamiento jurídico colombiano supone una jerarquía normativa que emana de la propia Constitución."

“(...) las normas constitucionales ocupan, sin discusión, el primer lugar dentro de la jerarquía del ordenamiento jurídico (...). Pero más allá de la supremacía constitucional, de la propia Carta también se desprende que las leyes expedidas por el Congreso dentro de la órbita de competencias que le asigna la Constitución, ocupan, en principio, una posición prevalente en la escala normativa frente al resto del ordenamiento jurídico. Así las cosas, tenemos que los actos administrativos de contenido normativo, deben tener por objeto el obedecimiento y cumplimiento de la ley, de donde se deduce su sujeción a aquella."

"La unidad del sistema jurídico, y su coherencia y armonía, dependen de la característica de ordenamiento de tipo jerárquico de que se reviste. La 
jerarquía de las normas hace que aquellas de rango superior, con la Carta Fundamental a la cabeza, sean la fuente de validez de las que les siguen en dicha escala jerárquica. Las de inferior categoría, deben resultar acordes con las superiores, y desarrollarlas en sus posibles aplicaciones de grado más particular. En esto consiste la connotación de sistema de que se reviste el ordenamiento, que garantiza su coherencia interna."

Se considera que pese a que las anteriores concepciones presentan trazos lógicotrascendentales, son algo simplistas, son confusas y no explican la complejidad del fenómeno con grado de pretensión de verosimilitud.

\subsection{Elementos del modelo complejo}

El modelo actual del sistema de fuentes colombiano es mucho más complejo de lo que parece y no responde a un simplista modelo jerárquico. La concepción clásica del sistema de fuentes deja por fuera del análisis elementos trascendentales para la explicación del fenómeno. Se piensa que el sistema de fuentes tiene de cierta forma la estructura del núcleo normativo de una formulación jurídica, junto con la identificación de una autoridad. Las relaciones entre concepciones voluntaristas, naturalistas y racionalistas, el carácter de las fuentes, los principios estáticos y dinámicos de la norma fundante, y la forma de solución de colisiones entre fuentes: son elementos que bosquejan el principal marco de investigaciones para la solución del problema de la determinación de las fuentes. Las primeras son consideradas como el origen de las formulaciones, la autoridad; las segundas refieren al carácter de la naturaleza de la fuente; las terceras refieren al contenido; y las cuartas, a las condiciones de aplicación. Aunque pueden argüirse otros elementos para analizar, se considera que con éstos son suficientes para la tarea de bosquejar los principales campos de investigación de las fuentes del derecho en el sistema jurídico interno.

\subsection{Relaciones de las fuentes Constitucionales}

Existen diferentes fuentes a nivel constitucional. Se ha hablado comúnmente de una parte dogmática y otra orgánica ${ }^{43}$. Empero, tal diferencia parece desvanecerse por múltiples factores. Quizás el más importante sea la sobre-trascendencia adquirida por los derechos fundamentales y su carácter normativo. Por tanto, las principales elucubraciones recaerán sobre ello. De forma general podría decirse que se establecen cuatro tópicos como fuentes de derechos fundamentales de máximo rango, desde el punto de vista de su origen o autoridad. Los derechos fundamentales establecidos en el texto constitucional, los derechos innominados, los derechos fundamentales obtenidos de la interpretación sistémica de la Constitución, y las regulaciones de

43 Cfr. Corte Constitucional T 406 de 1992. 
tratados internacionales que hacen parte del bloque de constitucionalidad ${ }^{44}$. Así pues, se establecen concepciones desde el voluntarismo, naturalismo y racionalismo.

Son concepciones voluntaristas el listado formal de derechos fundamentales establecidos en la Constitución y los derechos fundamentales establecidos por los acuerdos internacionales. Se dice que son voluntaristas porque de una $\mathrm{u}$ otra forma puede indicarse que obedecen al resultado de la voluntad del constituyente o de un acuerdo celebrado. Son concepciones naturalistas las elucubraciones referidas a los derechos innominados según refiere lo establecido en el artículo 94 de la Constitución. Se dice que son naturalistas porque tales derechos no provienen tanto de la voluntad de un ente sino más bien de la misma naturaleza del hombre, de aquellos derechos que son inherentes a la persona humana. Son concepciones racionalistas los derechos fundamentales extraídos de la constitución por interpretaciones sistémicas o inferenciales de la misma. Se dice que son racionalistas porque no provienen tanto de una declaración de voluntad o de concepciones naturalísticas sino que provienen o se derivan de las inferencias racionales de las disposiciones constitucionales $-\mathrm{o}$ de tratados- de los derechos fundamentales-.

La cuestión que ahora se aborda es la de establecer cuál regulación debe preferirse cuando existen diferentes regulaciones, de cada una de las fuentes antedichas, en diferentes sentidos. En primera medida, parece que pensar en un criterio de jerarquía resulta problemático ${ }^{45}$. Las regulaciones de las tres fuentes parecen tener la misma jerarquía. No obstante, también podría pensarse que existe una fuente que prima facie es superior y antecede a las demás, y es, para el caso, la fuente voluntarista. Lo referente a tal superioridad se revisa más adelante. Lo relativo a la procedencia se da por cuanto la naturalista, para el caso colombiano, es vigente por manifestación de la voluntarista y, la racionalista presupone la voluntarista o la naturalista. La concepción de derechos innominados es válida jurídicamente según se establece por la fuente voluntarista que a trazos generales representa las disposiciones constitucionales, y las concepciones de derechos fundamentales por interpretación sistemática de la Constitución, presuponen la existencia de unos derechos que tienen una fuente voluntarista o naturalista. Bajo esta concepción se piensa que la fuente voluntarista de la Constitución tiene una especie de jerarquía sobre la fuente naturalista y racionalista.

44 Cfr. Corte Constitucional, sentencias: C- 295 de 1993, 2.C- 225 de 1995, C- 578 de 1995, C- 135 de 1995, C- 135 de 1996, C- 358 de 1997, C- 708 de 1998, C- 038 de 2004, C 615 de 2004, C-1118 de 2005.

45 Existen casos en los cuales es fácil establecer la jerarquía. Por ejemplo, lo referido a la primacía de los derechos inalienables, o la trascendencia de los derechos de los niños. No obstante, estos casos no serán examinados. Pues, la revisión que se pretende efectuar está enmarcada en las bases sentadas, y no existen grandes conflictos en estos temas en los cuales se ha establecido de manera expresa cierta jerarquía constitucional. 
Además de lo anterior véase el caso de que la fuente voluntarista suele ser más precisa -aunque bien se puede caracterizar por su vaguedad-, que la fuente naturalista y racionalista. Si se le pregunta a un hombre medianamente racional qué es más fácil establecer como criterios de racionalidad para su conducta o para el actuar humano en general entre las siguientes alternativas: la voluntad establecida en un texto constitucional, los derechos naturales del hombre o unas inferencias racionalistas; fácilmente puede pensarse que la respuesta es apenas obvia. Es mucho más fácil pensar como fuente estable la voluntarista. La naturalista implica demasiados juicios de subjetividad -que no es que tampoco estén ausentes, del todo, pero si en menor grado, en la voluntarista-, la racionalista puede ostentar muchos resultados imprevisibles según en las premisas que se base.

Este establecimiento de la jerarquía de la fuente voluntarista es una forma de valorar la concepción formal de derechos fundamentales, según la cual son derechos fundamentales aquellos establecidos en el texto constitucional, empero, no dice nada respecto de sí existe una jerarquía entre las fuentes racionalistas y naturalistas. Prima facie, se podría decir que, existe prevalencia de las concepciones racionalistas sobre las naturalistas, pues, las concepciones naturales se encuentran por estabilidad y prevalencia sometidas a las racionalistas. Entre otras cosas, porque se ha demostrado en la historia que la razón fuerte prevalece sobre las concepciones naturalistas.

Además de existir el criterio de jerarquía como forma de solventar los problemas de las fuentes, puede pensarse en otro tipo de salvavidas, que fácilmente complementaría y allanaría el camino de lo establecido en los últimos párrafos. En la mayoría de ocasiones las fuentes glosadas no efectúan regulaciones de formas diferentes o contradictorias. El criterio de la jerarquía se da en el caso que pueda fácilmente establecerse para dirimir las controversias de regulaciones, empero en ocasiones no resulta ser necesario por el establecimiento de diferentes campos de acción. La relación de las diferentes fuentes puede verse como una relación de complementariedad. Así pues, los derechos innominados, concepción naturalista, se establecen como un complemento de los derechos fundamentales establecidos en el listado formal de la Constitución. En igual sentido, los derechos fundamentales establecidos por interpretación sistemática de la Constitución, concepción racionalista, se establecen como un complemento de los derechos fundamentales de catalogo formal. Ningún sentido tendría el establecer derechos fundamentales de máximo jerarquía de forma naturalista o racionalista si ya se establecieron de forma voluntarista. Esto es un argumento a favor de la primacía de las concepciones voluntaristas y a favor de la no regulación diferente sino complementaria, es decir: que las fuentes racionalistas y naturalistas complementan las voluntaristas, luego la relación de ellas, no es tanto de jerarquía, aunque si se presenta esta, sino más bien de espacios por regular. Luego los campos de cada uno serian diferentes.

Asimismo que el caso de la jerarquía y de los campos de regulación complementarios, puede verse como una forma de solventar los posibles conflictos de las fuentes mentadas: la decisión de un tercero. Tal tercero-corresponde a un 
órgano decisor, que para el caso ostenta como principal encarnación a la Corte Constitucional $^{46}$, que en la mayoría de las ocasiones contribuye a la prevención y creación de disputas sobre las fuentes. Este criterio en el orden jurídico interno se toma como el eslabón más reconocido por los miembros de la comunidad jurídica para la solución de los problemas de fuentes, pues establece con criterio de autoridad el alcance de las fuentes de derecho ${ }^{47}$. La Corte Constitucional trata de determinar los campos de regulación lineal de cada una de las fuentes, al establecer las posibles jerarquías en abstracto. Tales conceptos han resultado algo problemáticos, pues se han tratado de establecer campos y jerarquías en abstracto y de manera absolutista sin analizar la complementariedad de las fuentes y el carácter de éstas. La creación de disputas por parte de la Corte se debe principalmente a la variabilidad de criterios y la sobre-funcionalidad adquirida. No siempre ha tenido las mismas concepciones sobre la naturaleza y el alcance de las formulaciones jurídicas constitucionales, hasta el punto que la Corte puede caracterizarse por su cambiante disparidad de criterios ${ }^{48}$. La sobre-funcionalidad adquirida se debe al potencialismo para establecer el alcance de derechos fundamentales por interpretación sistemática o por derechos innominados y dotarlos de amplios contenidos y reducir el campo de acción legislativa. Lo cual, ha conllevado a que sean reiteradas las críticas, principalmente de legitimidad, a la Corte Constitucional al fijar no sólo en gran alcance los derechos fundamentales sino el contenido amplio de los derechos creados a partir del naturalismo y del racionalismo, pues, al parecer, excede sus competencias.

Por las funciones encargadas por la Constitución la Corte Constitucional está facultada para fijar el alcance de los derechos fundamentales. Pero ese alcance está dentro de la zona de penumbra de la formulación. Es decir, el alcance que fija la Corte no puede ser ni un demasiado poco ni un demasiado mucho en la formulación. Existen campos en los cuales es claro lo que la formulación dice, allí pues, la Facultad de la Corte es nula; igual que en el caso que se sabe que sobre eso la Constitución no dice nada, pues, la Corte no puede decir cosas diferentes a lo establecido por la formulación. En cambio, es discrecional en los campos donde no es claro lo que dice la Constitución. Luego, la función que cumple la Corte como órgano decisor no puede sobrepasar los parámetros de racionalidad mentados.

Surge un cuestionamiento por plantear. Lo que se cuestiona ahora es si la competencia para fijar los límites y el alcance de las formulaciones jurídicas puede ser dada por una norma de igual, o de inferior jerarquía a la de las mismas formulaciones jurídicas que trata de regular. La respuesta más obvia parece ser que no. Pues la formulación jurídica que regula las demás formulaciones jurídicas o que

46 Las funciones están en el artículo 241 de la Constitución Política.

47 Cfr. Ver las sentencias de la Corte Constitucional C 037 de 1995 y C 820 de 2006.

48 Piense por ejemplo en el caso de las tutelas contra las providencias judiciales o en el de la procedencia de la tutela en relaciones particulares o en el alcance de la autonomía de la voluntad y la libertad de persona. 
da competencia para ello ha de ser de una entidad superior a la de las demás so pretexto de no poder controlarlas. Caso contrario, si se está ante una formulación jurídica del mismo grado que da competencia a una entidad, tal competencia no puede tener la facultad para regular las demás formulaciones jurídicas, sino más bien para protegerlas o que no se les desmerezca su alcance natural y obvio, pues no podría inmiscuirse en su sentido racional de regulación de la formulación jurídica pues sobrepasaría sus potencialidades.

\subsection{Relación entre la Constitución y la ley}

Ahora bien, conviene analizar la relación que puede existir entre las disposiciones constitucionales y las disposiciones legales. Pues, aunque se ha tratado de imponer como única respuesta la concepción jerárquica esto no puede ser tomado tan a la ligera.

Puede decirse que, según la norma fundante, la Constitución Política ostenta la máxima validez formal. Por tanto, prima facie, podría decirse que su jerarquía no puede ser superada.

La Constitución, además de ostentar la máxima validez formal, es de carácter normativo -si bien no toda, partes de ella sí, especialmente lo que concierne a los derechos fundamentales-. Luego, ella ostenta la capacidad para mandar, prohibir o permitir cosas. La constitución dice que determinadas cosas deben hacerse, que otras no deben hacerse y que está permitido efectuar tales. Es decir: manda, prohíbe y permite.

Las formulaciones jurídicas mediante las cuales la Constitución manda, prohíbe o permite, son caracterizadas por su alto grado de abstracción, el cual, a su vez, es eslabón esencial para conllevar al aumento de ambigüedad e indeterminación. No obstante, podría decirse, que en algunos casos es fácil establecer lo que la Constitución manda, prohíbe o permite. Una persona medianamente racional, en algunos casos, puede establecer cuál es el carácter y el contenido de las formulaciones jurídicas. Esto, además, es un mínimo racional de comportamiento y de toma de decisiones. Así también, mediante la concepción del hombre medianamente racional, en ocasiones es fácil establecer aquello que la constitución no manda, prohíbe o permite. Empero, el principal inconveniente en este estadio se presenta cuando no es fácil establecer qué es lo que la constitución manda, prohíbe o permite.

Así pues, se considera adecuada la visión tripartita de la Constitución, ${ }^{49}$ según la cual: hay cosas que la Constitución dice, hay cosas que la Constitución no dice, y hay otras que no se sabe si dice. En primer lugar, cuando la Constitución dice algo es posible extraer de los postulados constitucionales cierto mensaje, un tal o

49 Cfr. BERNAL, Carlos. El Neoconstitucionalismo a Debate. Bogotá: Universidad Externado. 2007. $\mathrm{P}, 14$. 
cual enunciado; es decir, que la Constitución manda, prohíbe o permite algo. Por ejemplo, es posible extraer del artículo 29 de la Constitución un derecho fundamental al debido proceso, y ciertas sub-reglas mediante las cuales se puede especificar. En segundo lugar, hay cosas respecto de las cuales la constitución no dice nada, no es posible establecer que la constitución manda, prohíbe o permite algo. Por ejemplo, la forma como deben comportarse en la mesa las personas. En tercer lugar, hay cosas respecto de las cuales-no se sabe si la Constitución dice o no dice algo, si es posible afirmar que la Constitución manda, prohíbe o permite determinada cosa. Por ejemplo, si es posible el matrimonio de las parejas del mismo sexo, o si estas pueden ser consideradas como familia.

En ocasiones, se ha tratado de pasar por alto la anterior visión y establecer una regulación potencializada de las formulaciones jurídicas o una regulación minimalista de éstas. En el primer caso, se llega a pensar que las formulaciones jurídicas-constitucionales ostentan la capacidad de regular todas las relaciones que le importan al derecho; así pues, se habla, por ejemplo, de orden fundamental, de huevo jurídico originario ${ }^{50}$, o de la imposibilidad de establecer un modelo geográfico que delimite las áreas de la Constitución de las demás regulaciones jurídicas ${ }^{51}$. Lo cual conlleva a una supraconstitucionalización. En contrapartida de lo anterior, está la óptica según la cual la Constitución debe regular el menor número de asuntos posibles, o que la Constitución no ostenta fuerza normativa, así pues, se habla, por ejemplo, de un orden marco, de que la constitución no otorga ninguna directriz regulativa, o de supremacía de las regulación jurídica. Un demasiado poco en la regulación jurídica. Lo cual, conlleva una infra-constitucionalización.

Los problemas del demasiado mucho y del demasiado poco ${ }^{52}$ se han tratado de resolver mediante concepciones tales como la autonomía del legislador o los márgenes de acción. Bajo esta óptica las formulaciones constitucionales regulan ciertos espacios según se entiendan sus preceptos en sentido natural, según el alcance quede éstos puedan extraer personas racionales. En ocasiones la Constitución ordena ordenar, ordena prohibir, ordena permitir, prohíbe prohibir, prohíbe ordenar, prohíbe permitir, permite ordenar, permite prohibir y permite permitir. El legislador ostenta autonomía o márgenes de acción en aquellos espacios en los cuales no existen mandatos o prohibiciones, sino que existe permisión expresa o tácita para que regule de determinada forma. La permisión puede ser amplia o restringida a ciertos márgenes. Libertad que recae sobre la fijación de fines, medios o de ponderación ${ }^{53}$.

50 Cfr. ALEXY, Robert, Teoría de los derechos fundamentales, Madrid: Centro de Estudios Políticos y Constitucionales, Impreso en Solana e hijos, A.G., S.A., 2002. Epilogo, p, 16. Cfr. BERNAL, Carlos. El Neoconstitucionalismo a Debate. Bogotá: Universidad Externado. 2007. p, 5.

51 Ibíd. p, 3 .

52 Cfr. ALEXY, Robert, Teoría de los derechos fundamentales, Madrid: Centro de Estudios Políticos y Constitucionales, Impreso en Solana e hijos, A.G., S.A., 2002.

53 ALEXY, Robert, Teoría de los derechos fundamentales, Madrid: Centro de Estudios Políticos y Constitucionales, Impreso en Solana e hijos, A.G., S.A., 2002. Epilogo, p, 16 
En principio puede decirse que la libertad del legislador puede fácilmente establecerse cuando es claro lo que la Constitución manda, prohíbe o permite. Cuando es claro lo que se dice y lo que no se dice. Cuando, por lo menos, hombres medianamente racionales llegarían a conclusiones similares sobre aquello que se regula. Así, el legislador podría regular aquello que la Constitución ha permitido regular, y no está autorizado para regular lo que no ha sido permitido o lo permitido en sentido distinto a lo permitido.

Empero, en ocasiones no es fácilmente determinable o identificable si cierta situación es ordenada, prohibida o permitida. Podría pensarse que hombres racionales no podrían coincidir con la misma respuesta. En este caso, cuando no está claro si se dice o no se dice algo, se ha de permitir libertad al legislador, pues las regulaciones constitucionales en sentido de la relación con el legislador han de entenderse como permisiones en un constitucionalismo democrático. Así se espera que funcione. Es la primacía del voluntarismo en contraposiciones con las decisiones contra mayoritarias. Ya que el sentido de desarrollo de las formulaciones jurídicas ha sido encargado al legislador.

Lo anterior permite decir prima facie tres relaciones generales entre la constitución y la ley. La primera dice que existen ciertas regulaciones de la constitución a las cuales se debe subordinar la legislación. Es decir, existen algunos claros mandatos y prohibiciones de la Constitución o de las fuentes referidas hacia el legislador. Por tanto, éste debe hacer lo ordenado y omitir lo prohibido. Sería algo así como una norma fundante de carácter estático, pues las disposiciones legislativas se deben derivar de lo que dice la Constitución como se deriva lo particular de lo general. La legislación no podría infringir lo dispuesto constitucionalmente.

La segunda, dice que existen ciertos campos en los cuales el legislador es más libre, por cuanto se encuentra con espacios respecto de los cuales la constitución no ha previsto ninguna regulación o ha permitido ciertas regulaciones. Son campos en los cuales la Constitución no ha ordenado o prohibido alguna cosa. Luego, no existe una norma fundante de carácter estática sino más bien de carácter dinámica en aquellos campos de acción no regulados por la Constitución. El legislador es libre de regular de conformidad como estime adecuado.

La tercera dice que existen campos en los cuales no se sabe si la Constitución manda, prohíbe o permite algo, con lo cual, al mismo tiempo no se sabe si el legislador debe hacer, no hacer o le está permitido hacer algo. Por el principio democrático se entenderá que legislador puede establecer las regulaciones que estime en estos campos, pues no ha de tener como parámetro racional de limitación aquellos casos en los cuales no sea posible establecer si la Constitución dice o no dice algo.

Así pues, el desarrollo más puntual de la Constitución lo representan las disposiciones del legislativo. Lo que se ha expedido por el órgano competente, por el procedimiento signado y que no contravenga una regulación constitucional. En este orden de ideas el parámetro de racionalidad de la conducta de las personas ha de ser el desarrollo legislativo como desarrollo constitucional. Ello, se debe principalmente 
a cuatro diferentes tipos de argumentos, los cuales, no son los únicos ni quizás los más importantes.

El primero, por cuanto la ley resulta ser bajo la óptica referida, el desarrollo de la Constitución, un acto de deber que desarrolla el acto de poder. La ley es un acto ejecutivo de la Constitución en cuanto hace lo ordenado, obvia lo prohibido y, si es el caso, ejecuta lo permitido. Especifica, pues, lo establecido en el texto constitucional. El segundo, es referido a la necesidad de legitimar el derecho mediante un procedimiento discursivo ${ }^{54}$. El derecho producto de un procedimiento discursivo es el encargado de unir el lazo social desintegrado. El tercero, dice que el mejor mecanismo de racionalidad para la toma de decisiones es la ley. Por lo abstracto e indeterminado de las disposiciones constitucionales, la vaguedad e indeterminación a que ello conlleva, la ley se muestra menos abstracta y más estable. El cuarto, dice que la ley se presume constitucional, y quien pretenda desligar esto tiene la carga de la prueba de demostrarlo. Si es ley y está vigente se entiende como desarrollo de la Constitución, hasta que el órgano encargado tome una decisión en otro sentido.

Para aquellos eventos en los cuales se cuestione la validez de las disposiciones legislativas sobre el texto constitucional se ha encargado a un ente para que establezca su conformidad o disconformidad. Empero ello debe precisarse. En casos dudosos o cuestionados existe un ente con autoridad para vincular ciertas interpretaciones de la Constitución, para decir lo que dice la Constitución. De forma general la Función de la Corte es de interpretación con autoridad. No se trata tanto de declarar la constitucionalidad o inconstitucionalidad de las leyes sino más bien de precisar el alcance de las formulaciones constitucionales. Es decir, de si el legislador se sobrepasó en los márgenes establecidos, sobre la fijación de medios de fines o en la ponderación. Para que, luego de ellos los hombres medianamente racionales ostenten la capacidad para decir si se ha contradicho o no la Constitución.

\subsection{El lugar de la jurisprudencia}

La Corte Constitucional, en una postura progresista, ha intentado establecer la obligatoriedad del precedente ${ }^{55}$. Es decir, trata de dotarlo de cierta obligatoriedad que pese a que no es absoluta, obliga al juez a aducir razones razonables o imperiosas cuando desee apartarse de él.

El fundamento de la Corte para implicar la obligatoriedad del precedente presupone la concepción del derecho como integridad ${ }^{56}$, un juez capacitado y unos

54 En este sentido se cree que el derecho es el único elemento que sobrevive después de la pérdida de la legitimación de las imágenes clásicas de legitimación, por tanto es el mejor mecanismo para la integración social. HABERMAS, Jurguen, Facticidad y Validez; Madrid: Editorial Trota, 1998. p, $1-82$.

55 Cfr. C-836 de 2001, C 350 de 2009 ,

56 Tal concepción resuena muy afín con posturas dworkinianas. 
valores imperiosos. Es esto, tal vez, una tendencia muy anglosajona. La visión del derecho como integridad hace que el fundamento del fallo deba sopesar razones éticas, morales y políticas. Por tal presuposición, del derecho como integridad, se le imprime al juez una función creativa, mediante la cual este debe integrar los diferentes elementos del ordenamiento jurídico con elementos éticos, morales o políticos.

Por tal motivo, el juez adquiere un rol trascendente. Las exigencias para el juez en este estadio son altas. El juez no es un servidor de la ley, no es pasivo, tiene funciones constructivas que permiten hallar respuestas adecuadas en el ordenamiento ${ }^{57}$. La ley necesita, en esta concepción, acercarse a la sociedad y a consideraciones metafísicas. Por tanto, la función del administrador de justicia no es cognitiva sino creativa.

El derecho como integridad, según la Corte, representa la consecución o la pretensión de alcance de dos valores imperiosos en el ordenamiento: la seguridad jurídica y la igualdad ${ }^{58}$. Dice que el precedente como desarrollo de la integridad del ordenamiento jurídico da seguridad a éste, pues, los jueces se encuentran obligados a seguir los lineamientos de los órganos de cierre, con ello hace posible que exista conciencia de cierta estabilidad normativa, impide así la arbitrariedad que puede ser cometida cuando los jueces ostentan la facultad de interpretar la ley a su arbitrio. A su vez, la integridad conlleva a la igualdad en trato y protección, pues, si se tiene ciertos criterios uniformes y estables de racionalidad las decisiones de los jueces respetarán el derecho de igualdad de los que acuden a la jurisdicción.

Algunas de las concepciones que fundamentan la obligatoriedad del precedente parecen no encontrar recibo en las especificaciones positivas de la Constitución o del derecho legislado. Por lo cual, se ha hecho necesario que la Corte acuda a ciertas diferenciaciones en aras a hacer empatar la concepción del precedente con ciertas disposiciones. Para ello, la Corte se vale de ciertas distinciones tales como jurisprudencia, dichos de paso o razón de decidir. En donde, establece, por ejemplo, que el criterio auxiliar que refiere la Constitución es a la jurisprudencia y a los dichos de paso. En cambio, la razón de decidir, la fuente del precedente, está fincada en la concepción de ley, como derecho. Así, pues, el precedente no haría parte de los criterios auxiliares de interpretación sino que bajo el rótulo de razón de decidir se deslizaría de forma subrepticia dentro de las fuentes formales.

Empero, se estima que tal concepción es equivocada. Pueden aducirse múltiples razones para ello. No obstante, se enuncian las más significativas. En primer lugar, se dice que pese a que existe una tendencia al acercamiento actual de las concepciones del sistema romano-germano y el anglosajón, las diferencias existen, $y$, antes de llegar a una unificación deben compenetrarse más referentes que la simple obligatoriedad del precedente, el diseño del sistema, su estructura, es de derecho legislado. En segundo

57 Se toma el adjetivo de adecuadas, por cuanto, en este campo la solución dada por el juez no se considera, como en la base de la inspiración, única. 
lugar, se dice que la ley es desarrollo inmediato de la Constitución, en cambio la jurisprudencia es desarrollo inmediato de la ley y mediato de la Constitución, la ley es intermediario entre la Constitución y la ley en un ordenamiento romano-germano, si se quisiera pasar la ley para acudir a la jurisprudencia se daría un salto inadecuado. En tercer lugar, se dice que existe preferencia de los juristas y los ciudadanos en cuanto a criterios de racionalidad, respecto de la ley que en un complejo entramado de argumentos de los cuales hay que hacer una ideal tarea hermenéutica para deslindar unos de otros y ver qué jerarquía tienen. En cuarto lugar, un argumento positivista dice que el artículo 230 de la Constitución es claro cuando indica que la jurisprudencia ${ }^{59}$ es un criterio auxiliar de interpretación de la ley, pues, la sujeción es estricta a la ley; no puede pensarse que el constituyente prefirió referirse a un criterio subordinado y pasó en silencio uno de mayor jerarquía. En quinto lugar, se dice que es más adecuado en un Constitucionalismo democrático, aferrarse a las decisiones mayoritarias que a las de cierta "elite". En sexto lugar, se dice que la exigencia de la Corte de argumentar para apartarse de los precedentes es superflua, pues, la toma de decisiones judiciales de fondo va a estar siempre motivada, y si se toma una decisión contraria a la establecida en el precedente es porque el juez utilizó otro criterio de racionalidad, lo cual, simplemente, que el juez rechazó los argumentos de la Corte porque le dio preferencia a los que él estableció. Además, existe una estructura orgánica, mediante la cual el superior funcional, puede, mediante ciertas condiciones, imponer su criterio al subordinado.

Lo anterior debe matizarse con unas diferenciaciones que, pese a que son obvias, se consideran importantes. El caso de la jurisprudencia de la Corte Constitucional es diferente al caso de las otras altas Cortes. La Corte Constitucional, en algunos casos emite jurisprudencia vinculante y obligatoria para una generalidad. Por ejemplo, en los casos de control abstracto de constitucionalidad, o en el caso de sentencias de unificación para las personas integradas en el supuesto. Empero en ocasiones, hace aseveraciones sobre la Constitución. Cuando habla de la Constitución y fija el sentido y el alcance de derechos fundamentales, hay que ver el caso en el cual claramente dice cosas que vienen más acá o van más allá, de las que dicen las palabras de la Constitución, cuando la Corte dice cosas más allá de las que dice la Constitución no es obligatorio, constituye un criterio de autoridad. Cuando dice algo acerca de la ley, obra en el mismo sentido, los alcances de las interpretaciones dadas por la Corte a las disposiciones legislativas son criterios de autoridad que pueden seguirse o no seguirse y que se justifican siempre y cuando estén en las zonas de discrecionalidad.

59 La distinción dada entre jurisprudencia, dichos de paso y razón de decidir, es para el caso: artificiosa. Presenta múltiples contradicciones, pues, por ejemplo, excluiría de la regulación constitucional lo que se quiere hacer obligatorio. 


\section{Tercera sección}

La mayoría de los problemas de la aplicación del derecho se generan en la justificación externa de las premisas. Especialmente, en aquellas de carácter normativo. Pues, pocas veces se discute el paso de las premisas a la conclusión, la mayoría de los debates recaen en desacuerdos acerca de la regulación jurídica del caso. El establecer cuál es la regulación a seguir es importante para la toma de decisiones judiciales y como criterio de racionalidad de los particulares.

Si se relaciona, la autoridad, el carácter, el contenido y la ocasión de aplicación, lo que se tiene respecto de las fuentes constitucionales es lo siguiente. Existe prima facie en el ámbito constitucional prelación de la fuente voluntarista sobre la racionalista y naturalista. En relación con tal tercio, la fuente voluntarista es una fuente que debe utilizarse y las otras dos son fuentes que pueden utilizarse. Ello se da respecto de campos regulados expresamente por la fuente voluntarista. Empero, hay que ver también que las dos últimas, en cuanto a sus campos de regulación, constituyen un complemento de la primera. La ocasión de aplicación de tal fuente voluntarista como necesaria refiere a la regulación expresa de la Constitución en determinado caso. Excepcionalmente, si no existe campo de regulación de la fuente voluntarista, de las otras dos, la que lo regule es la fuente que debe utilizarse para el caso. Se transforma una fuente que era posible en necesaria, pasa de lo permitido a lo obligatorio. De lo posible a lo necesario. Debido, a que las ocasiones de aplicación, por la falta de regulación del contenido, han hecho imperioso tal tránsito.

Si a lo descrito en el párrafo anterior se le agrega la relación con la ley, los elementos parecen variar. Para la toma de las decisiones jurídicas la ley, como elemento emanado de la voluntad, es una fuente que debe usarse. Es el criterio inmediato de desarrollo de la constitución y el mejor- o al menos el menos problemático- criterio de racionalidad. La consideración de la ley como criterio que debe usarse, como elemento necesario, está limitada por las disposiciones constitucionales, a aquellos campos en los cuales haya sido permitido expresa o tácitamente por la Constitución legislar en determinados sentidos: fijar fines, medios o ponderar. Es decir, que las ocasiones de aplicación de tal criterio se encuentran supeditadas a la permisión de legislar. Pues, excepcionalmente, en caso de que la Constitución haya regulado de forma expresa determinado asunto, la fuente que debe usarse es la constitucional, en tal caso el contenido de las formulaciones jurídicas cambian la ocasión de aplicación. Con lo cual, se convierte los aspectos regulados por el legislador en elementos posibles pero no necesarios.

La jurisprudencia prima facie es fuente auxiliar. Ella es una fuente que puede usarse. No es necesaria sino posible. Es un acto de deber respecto de los actos de poder. Su origen se remonta a una entidad que no está encargada de producir derecho formal. Empero, su utilización depende de su no contradicción con las disposiciones legislativas o constitucionales. Es un elemento de soporte. Pese a los acercamientos dados en tiempos recientes entre el modelo anglosajón y el romano-germano, aún la 
estructura general de cada modelo es diferente. La jurisprudencia ha de ser desarrollo inmediato de la ley y mediato de la Constitución. Es un acto ejecutivo respecto del acto productivo. La ley constituye un criterio más racional que el entramado de argumentos judiciales. Y, pues, por último, porque así lo ha dispuesto la Constitución.

\section{REFERENCIAS}

Aguiló, J. (2000).Teoría general de las fuentes del Derecho (y del orden jurídico). Editorial Ariel S. A. Barcelona, 2.000.

Aarnio, A. (1991). Lo racional como razonable. Un tratado sobre la justificación jurídica. Trad. de Ernesto Garzón Valdés. Madrid: Centro de Estudios Constitucionales,

Alexy, R. (2004). El concepto y la validez del derecho. Barcelona: Gedisa.

Alexy, R. (2002). Teoría de los derechos fundamentales, Madrid: Centro de Estudios Políticos y Constitucionales, Impreso en Solana e hijos, A.G., S.A.,

Alexy, R. (2004). Teoría del Discurso y los Derechos Humanos, Bogotá: Universidad Externado de Colombia.

Bernal, C. (2007). El Neoconstitucionalismo y la normatividad en el derecho. Bogotá: Universidad Externado de Colombia.

Bernal, C. (2007). El Neoconstitucionalismo a Debate. Bogotá: Universidad Externado.

Bobbio, N. (2002) Teoría General del Derecho. Bogotá: Editorial Temis. 2.002.

Bobbio, N. (1997). El problema del positivismo jurídico. Santa Fe de Bogotá: Editorial Temis.

Bourdieu, P. T, G. (2000). La fuerza del derecho, en Derecho Reflexivo; Bogotá: Siglo de Hombres Editores,

Fassó, G (1996). Historia de la Filosofía del Derecho. Madrid: Ediciones Pirámide, S.A.

Feteris, E, (2007). Fundamentos de la argumentación Jurídica: revisión de las teorías, Bogotá: Universidad Externado de Colombia,

Foucault, M, (2003). Vigilar y Castigar; Argentina: siglo veintiuno editores.

Habermas, J, (1998). Facticidad y Validez; Madrid: Editorial Trota. .

Kelsen, H (2000).Teoría Pura del Derecho, México: Editorial Porrúa,

Sáchica, L. (2000). Nuevo constitucionalismo Colombiano. Bogotá:

Santos, Boaventura de Sousa. (1998).La globalización del derecho. Los nuevos caminos de la regulación y la emancipación, Bogotá: Universidad Nacional de Colombia - facultad de Derecho, Ciencias Políticas y Sociales Instituto Latinoamericano de Servicios Legales Alternativos (ILSA),

Schmitt, Carl (1983): El concepto de lo político, Buenos Aires, Folios. 
Viehweg, Theodor. (1964). Tópica y jurisprudencia, traducción de Díez-Picazo, Luis (1964), España: Taurus.

Schmitt, Carl (1982): Teoría de la Constitución, Madrid, Alianza Editorial.

Vigo, R, (2003).El Iusnaturalismo actual. México: Fontamara. 2003.

Wright, Georg Henrik Von. (1997).Normas, verdad y lógica. Fontamara, México. 